Article

\title{
Impedimetric Detection of Femtomolar Levels of Interleukin 6, Interleukin 8, and Tumor Necrosis Factor Alpha Based on Thermally Modified Nanotubular Titanium Dioxide Arrays
}

\author{
Katarzyna Arkusz * (D) and Ewa Paradowska \\ Department of Biomedical Engineering, Faculty of Mechanical Engineering, University of Zielona Gora, \\ Licealna 9 Street, 65-417 Zielona Gora, Poland; e.paradowska@ibem.uz.zgora.pl \\ * Correspondence: k.arkusz@iimb.uz.zgora.pl; Tel.: +48-68-328-2629
}

Received: 9 November 2020; Accepted: 30 November 2020; Published: 30 November 2020

\begin{abstract}
An inexpensive, easy to prepare, and label-free electrochemical impedance spectroscopybased biosensor has been developed for the selective detection of human interleukin 6 (IL-6), interleukin 8 (CXCL8, IL-8), and tumor necrosis factor (TNF $\alpha$ )-potential inflammatory cancer biomarkers. We describe a, so far, newly developed and unexplored method to immobilize antibodies onto a titanium dioxide nanotube (TNT) array by physical adsorption. Immobilization of anti-IL-6, anti-IL-8, and anti-TNF $\alpha$ on TNT and the detection of human IL-6, IL-8, and TNF $\alpha$ were examined using electrochemical impedance spectroscopy (EIS). The impedimetric immunosensor demonstrates good selectivity and high sensitivity against human biomarker analytes and can detect IL-6, IL-8, and TNF $\alpha$ at concentrations as low as $5 \mathrm{pg} / \mathrm{mL}$, equivalent to the standard concentration of these proteins in human blood. The calibration curves evidenced that elaborated biosensors are sensitive to three cytokines within $5 \div 2500 \mathrm{pg} / \mathrm{mL}$ in the $0.01 \mathrm{M}$ phosphate-buffered saline solution (pH 7.4).
\end{abstract}

Keywords: titanium dioxide nanotubes; interleukin 6; interleukin 8; tumor necrosis factor; immunosensor; electrochemical impedance spectroscopy

\section{Introduction}

Chronic inflammatory reactions have received much attention in recent years due to wrong effector mechanisms or immune response [1]. Both may be harmful or cause life-threatening diseases such as cancer, septic shock, aortic valve stenosis, Alzheimer's, heart attack, kidney failure, and surgical complication. Proinflammatory cytokines first appear in the area of damaged tissue (i.e., cancer cell division) and play an important role in transmitting signals into leukocytes through endothelium activation [2]. Several publications [3-5] have appeared in recent years documenting the increased expression of interleukin 8 (CXCL8, IL-8), interleukin 6 (IL-6), tumor necrosis factor (TNF $\alpha$ ) in cancer cells, infiltrating neutrophils, endothelial cells and tumor-associated macrophages.

IL-8 affects gene expression (via regulation of numerous transcription factor activities), modulates the cellular proteome, and affects cell cytoskeleton organization. IL-8 signaling increases the proliferation and survival of endothelial cells, promotes angiogenic responses, and potentiates endothelial cell migration and the infiltration of neutrophils in the affected area [5]. This confirms the significant role of IL-8 within the inflammatory microenvironment. Accordingly, IL-8 expression correlates with the course of septic shock, angiogenesis, and metastasis of tumors.

Several works [4] recently showed the increased expression of IL-6 and/or its receptors in bone metabolism, hematopoiesis, pathogenesis, inflammatory responses, and cancer progression. 
The increased concentration of IL-6 is observed in lung, uterus, kidney, colon, breast, and ovarian cancers. It was confirmed that its level is correlated with the size and staging of the tumor [6].

The biological function of TNF $\alpha$ is extensive due to membrane receptors affecting various cells. The biggest influence was observed in the immunological reactions and tumor cells [4]. Many authors demonstrated the anticancer effects of TNF $\alpha$ due to tumor cell proliferation inhibition, stimulating apoptosis, and increased cell differentiation. TNF $\alpha$ inhibits angiogenesis and accelerates the clotting of blood feeding the tumor. However, not all types of cancers occur with the above-described phenomena. Hairy cell leukemia, or chronic lymphocytic leukemia B-ventricular, exhibits the severity of the disease due to the increased TNF $\alpha$ concentration [7].

Due to the extensive biological significance of IL-6, IL-8, and TNF $\alpha$, fast and common detection/monitoring of these cytokines in the human body are needed.

Current methods for detection of IL-6, IL-8, and TNF $\alpha$ are based on enzyme-linked immunosorbent assay (ELISA) tests $[8,9]$. These methods require sophisticated instrumentation, aseptic handling, highly qualified personnel. In addition, these techniques are time-consuming and costly. For this reason, research on new biosensors has become very popular in recent years. Previous research [10-27] has been carried out to obtain high sensitivity and specificity for direct detection of selected antigens using various commonly available methods, such as electrochemical, optical, fluorometric, radioimmunoassay. Recently elaborated IL-6, IL-8, and TNF $\alpha$ biosensors [10-27] are based on gold, combination tapered fiber, polysilicon nanowire, dendrimers, and other nanomaterials. The lowest detection limits of IL-6, IL-8 and TNF $\alpha$ were reached at 0.01 [21], 32 [23], and $0.48 \mathrm{pg} / \mathrm{mL}$ [25], respectively. These detection limits were achieved using confocal optics [21], fluorescence microscopy [23], and microresonators [18] — costly, and time-consuming methods requiring sample preparation or multiple functionalized biosensor platforms consisting of carbon nanotubes, gold nanoparticles, and $\mathrm{SiO}_{2}$ array.

However, recent research, allowing for obtaining a low limit of detection, required a complicated methodology for preparing the electrode. Electrochemical biosensors have recently attracted much attention due to their simple design and high sensitivity [28]. Among all the electrode materials used for biosensing applications, titanium dioxide $\left(\mathrm{TiO}_{2}\right)$ represents an excellent material with good electrical properties, biocompatibility, and excellent bioactivity [29-32]. The surface topography, and electrical and adsorption properties of titanium nanotubes are important factors for the successful immobilization of biological substances [33-36]. Due to TNT's low corrosion potential, the direct immobilization of protein is very simple and effective. Semiconductive titania nanotubes are shown to be excellent substrates for inorganic and biological electrocatalysts. TNT formed on Ti, or its alloy is ready to use as a biosensor electrode and has good implantology properties [37].

Some already published examples of using $\mathrm{Ti} / \mathrm{TiO}_{2}$ layers as the biosensor platforms are very promising [38-43]. The first attempt at hydrogen peroxide $\left(\mathrm{H}_{2} \mathrm{O}_{2}\right)$ biosensor was made by Liu [38]. The detection limit of the elaborated biosensor was $1.2 \mu \mathrm{M}$ using horseradish peroxidase with thionine and amperometric detection. Further studies on the detection of $\mathrm{H}_{2} \mathrm{O}_{2}$ using the TNT array were carried out by Kafi [39], Guo [40], Chen [41], Kafi [42], and increased the LOD: 2, 0.92, 0.18, and $0.08 \mu \mathrm{M}$, respectively. $\mathrm{TiO}_{2}$ nanotubes have also been investigated as an electrode material for glucose detection [43]. The lowest detection limit of glucose was reached at $1.5 \mu \mathrm{M}$ [43] using glucose oxidase, immobilized via glutaraldehyde on polypyrrole-modified TNT by amperometric technique.

Ever since the development of the first biosensor based on TNT, much attention has been focused on improving the response performances of enzyme electrodes for biosensor applications. The authors used mediators like chitosan [44], hemoglobin [45], and methylene blue [46], and functionalized TNT by gold [34,35], silver [33], glassy carbon [47], or used processes of visible-light-activation [48], and carbonization [49]. The TNT based biosensor was also used for the detection of methanol electrooxidation [50], luminol [51], penicillin-binding protein [52], and atrazine [53].

In the present study, we have developed sensitivity, simple, label-free, and easy to use in point-of-care immunosensor for IL-6, IL-8, and TNF $\alpha$ detection, based on the titanium dioxide nanotube-based nanoelectrode. Thermal modification, electrochemical, and adsorption analysis 
explain the physisorption mechanism of the antibody on the TNT layer and substantially supplement the existing literature reports. A newly elaborated method to immobilize antibodies onto TNT by physical adsorption has allowed us to detect IL-6, IL-8, and TNF $\alpha$ protein at 5 pg/mL (192, 625, and $295 \mathrm{fM}$, respectively) in phosphate buffered saline (PBS). The obtained limit of detection is lower than in the standard ELISA kit, matching the physiological level, whereas the higher concentration of cytokines includes the levels corresponding to inflammation states. The total time of determining the concentration of IL-6, IL-8, and TNF $\alpha$ was reduced from 6 to $2 \mathrm{~h}$.

\section{Materials and Methods}

\subsection{Materials}

Titanium foil (thickness $0.5 \mathrm{~mm}, 99.99 \%$ trace metal basis), phosphate buffered saline (PBS, $0.01 \mathrm{M}$, $\mathrm{pH} 7.4)$, ammonium chloride $\left(\mathrm{NH}_{4} \mathrm{~F}, 99.5 \%\right)$, and ethylene glycol $\left(\mathrm{C}_{2} \mathrm{H}_{6} \mathrm{O}_{2}, 99.8 \%\right)$, were purchased from Sigma-Aldrich (St. Louis, MO, USA). The ELISA kits for human IL-6 (ELH-IL6-001), IL-8 (ab100575) and TNF $\alpha$ (ET2010-1) protein were purchased from RayBiotech (Peachtree Corners, GA, USA), Abcam (Cambridge, UK), AssayPro (St. Charles, MO, USA), respectively, and stored at $4{ }^{\circ} \mathrm{C}$ to prevent protein denaturation. The impedimetric biosensor detection scheme uses monoclonal antibodies (Mab) that form a pair of sandwich assays in human cytokines.

All electrochemical measurements-i.e., anodization of titanium foil, open circuit potential (OCP), and electrochemical impedance spectroscopy (EIS) measurements-were carried out with the AutoLab PGSTAT 302N potentiostat/galvanostat (Eco Chemie, Utrecht, The Netherlands) equipped with a voltage multiplier $(30 \mathrm{~V})$ using the standard three-electrode configuration with a titanium electrode and $\mathrm{Ti} / \mathrm{TNT}$ as the working electrode, the standard $\mathrm{Ag} / \mathrm{AgCl}^{-}$silver chloride electrode $\left(\mathrm{E}_{\mathrm{Ag} / \mathrm{AgCl}}=0.222 \mathrm{~V}\right)$ as the reference electrode, and a platinum foil as the auxiliary electrode at $25 \pm 1^{\circ} \mathrm{C}$.

\section{2. $\mathrm{TiO}_{2}$ Nanotubes Fabrication}

The titanium foil was sonicated in acetone, ethanol, and distilled water and dried in nitrogen. The formation of nanotube oxide layers was performed by electrochemical anodizing in various ethylene glycol solution concentrations with $0.65 \% \mathrm{wt} . \mathrm{NH}_{4} \mathrm{~F}$. The formation process consists of two stages: the first potentiodynamic and the second potentiostatic. In the beginning, the foil was polarized up to $17 \mathrm{~V}$ with a scan rate of $0.5 \mathrm{~V} / \mathrm{s}$ and then was kept at that potential in the same electrolyte for a further $3750 \mathrm{~s}$. Field emission scanning electron microscopy (FESEM, JEOL JSM-7600F, Tokyo, Japan) and energy-dispersive X-ray spectroscopy (EDS, INCA, Oxford Instruments, Oxford, UK) was used to investigate surface morphology and chemical composition.

\subsection{Thermal Modification of TNT}

The obtained TNT layers were annealed in argon at $550{ }^{\circ} \mathrm{C}$ for $2 \mathrm{~h}$ with the heating rate of $6{ }^{\circ} \mathrm{C} / \mathrm{min}$ to the desired annealing temperature. Field emission scanning electron microscopy (FESEM, JEOL JSM-7600F, Tokyo, Japan) and energy-dispersive X-ray spectroscopy (EDS, INCA, Oxford Instruments, Oxford, UK) were used to investigate surface morphology and chemical composition.

\subsection{Evaluation of the Open Circuit Potential (OCP) and Contact Angle of TNT}

The OPC measurements were performed using Ti/TNT samples before and after thermal modification immersed in PBS solution (0.01 M, $50 \mathrm{~mL}, \mathrm{pH} 7.4)$ for $1800 \mathrm{~s}$.

Dynamic contact angle measurements were performed using distilled water at room temperature using a PG-3 Goniometer equipped with a microscope, a camera, and an integrated micro-pump, which deliver accurate droplets in $0.5 \mu \mathrm{L}$ steps. 


\subsection{Functionalization of TNT Layers with Antibodies and IL-6, IL-8, TNF $\alpha$ Detection}

IL-6, IL-8, TNF $\alpha$ were immobilized on the biosensor platform using the simple drop coating method at room temperature. Annealed in argon, Ti/TNT samples were incubated with $10 \mu \mathrm{L}$ of IL-6, IL-8, TNF $\alpha$ antibody solutions for different times and then treated with $10 \mu \mathrm{L}$ of IL-6, IL-8, TNF $\alpha$ antigens solutions of various concentrations ranging from 0 to $2500 \mathrm{pg} / \mathrm{mL}$. After the immobilization process, each sample was washed with a buffer solution $(3 \times 100 \mu \mathrm{L})$ to remove non-specifically bound biomolecules. Spectrophotometric measurements were performed using a Hitachi UV-2310II Spectrophotometer at a wavelength of $450 \mathrm{~nm}$.

The response of impedimetric immunosensor was recorded using Electrochemical Impedance Spectroscopy (EIS) method. Impedance analysis was performed over a frequency range from $0.1 \mathrm{~Hz}$ to $100 \mathrm{kHz}$ (10 points/decade), at zero DC potential, with an AC amplitude of $10 \mathrm{mV}$ and an integration time of $10 \mathrm{~s}$. The effects of electrolyte $\mathrm{pH}$ on the response of elaborated biosensors were studied using IL-6, IL-8, and TNF $\alpha$ antigens with a concentration of $300 \mathrm{pg} / \mathrm{mL}$.

\section{Results and Discussion}

\subsection{Characteristics of Titanium Dioxide Nanotubes}

As shown in Figure 1, the TNT formed in the anodizing process, according to the applied parameters, results in a uniform $1000 \pm 100 \mathrm{~nm}$ thick layer of vertically aligned nanotubes (Figure 1a) with a diameter of about $50 \pm 5 \mathrm{~nm}$. SEM pictures show homogenous arrays of opened from the top, closed at the bottom, and vertically oriented nanotubes completely covering the titanium foil. No damage was observed on the TNT layer after annealing (Figure 1b). Obtained SEM images confirm that the thermal modification does not influence TNT layer homogeneity and morphology-its height and diameter were not changed.
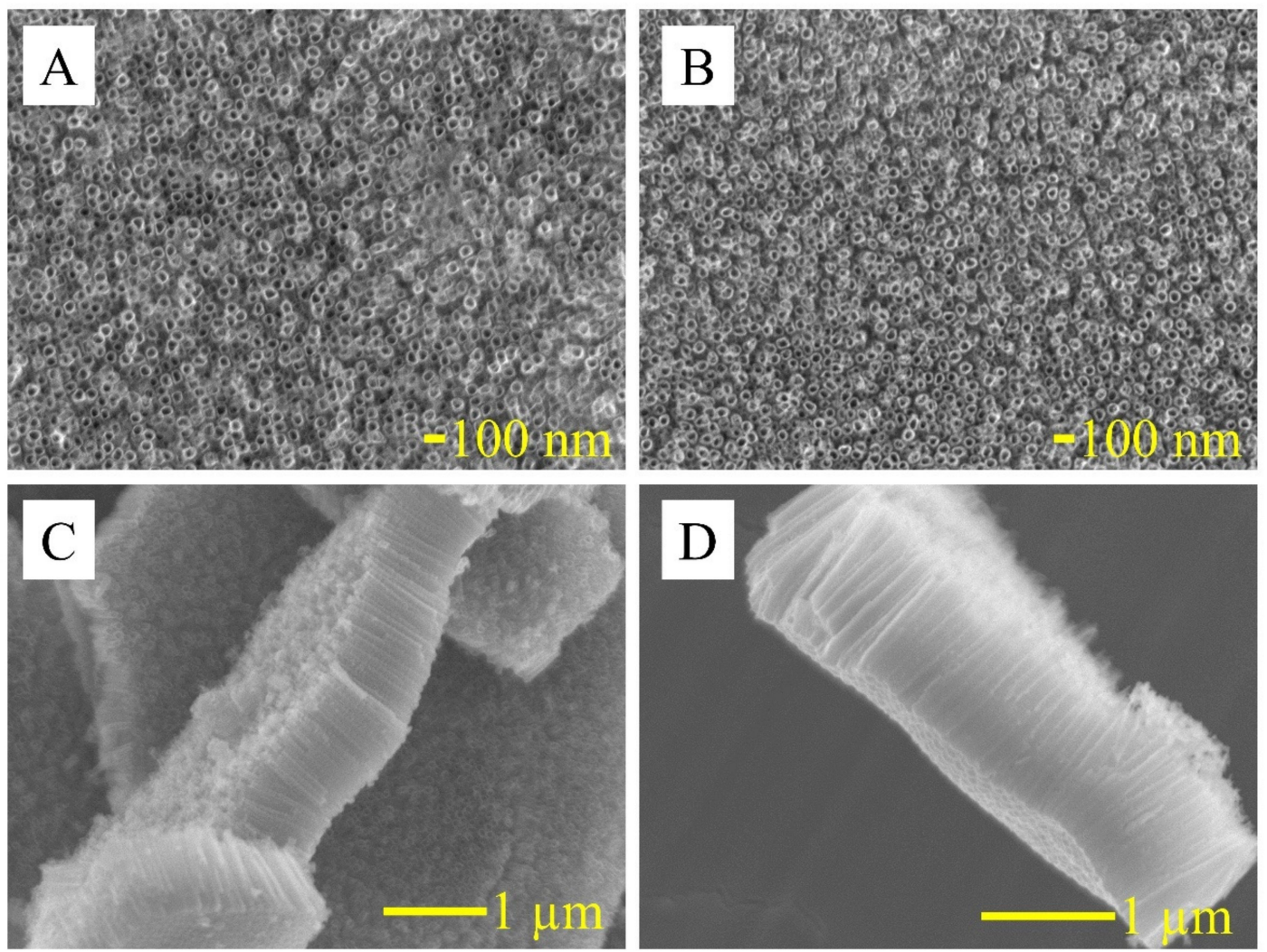

Figure 1. SEM images of top view (A,B), and cross view (C,D) of TNT (A,C), and TNT annealed in argon $(\mathbf{B}, \mathbf{D})$ at $550^{\circ} \mathrm{C}$ during $2 \mathrm{~h}$. 
The height and diameter of TNT were chosen based on previous electrochemical analysis, indicating the most favorable sensing and biosensing properties [31]. This structure is characterized by OCP values close to zero, one of the smallest impedance module, and a high Ipa/Ipc ratio for potassium ferricyanide, which confirms good conductivity and good adsorption properties of this structure [29]. Moreover, titanium nanotubes annealed at a temperature of $550{ }^{\circ} \mathrm{C}$ in an argon atmosphere have more anatase structures that promote biological element adsorption [32]. However, previous experiments do not attempt antibody immobilization on the TNT surface.

The EDS microanalysis results for samples formed in ethylene glycol and thermally modified in argon are presented in Table 1. According to the formation conditions, the results showed the difference in concentrations of elements in the $\mathrm{TiO}_{2}$ nanotubes layer. After thermal treatment, fluoride is not identified, and obtained titanium oxide is non-stoichiometric. Fluoride uptake caused an increase in oxygen content in TNT annealed in argon (33.9\%). Annealing in argon could change the ingredients of the oxide layer leading to the formation of oxygen vacancies. The possible explanation is reducing titanium ions from $\mathrm{Ti}^{4+}$ to $\mathrm{Ti}^{3+}$ ions and the formation of oxygen vacancies [32-35].

Table 1. Elemental investigation of titania nanotubes ( $50 \mathrm{~nm}$ diameter, $1000 \mathrm{~nm}$ thickness) before and after thermal modification (annealing in argon, in temperature $550{ }^{\circ} \mathrm{C}$ for $2 \mathrm{~h}$ ).

\begin{tabular}{ccc}
\hline (wt.) & Non-Annealed & Annealed in Argon \\
\hline $\mathrm{Ti}(\%)$ & $65.9 \pm 4.2$ & $66.1 \pm 3.1$ \\
$\mathrm{O}(\%)$ & $25.6 \pm 2.6$ & $33.9 \pm 1.5$ \\
$\mathrm{~F}(\%)$ & $8.6 \pm 3.5$ & - \\
\hline
\end{tabular}

The Open Circuit Potential (OCP) curves (Figure 2) show stable potential recorded values during the $1800 \mathrm{~s}$. Small current oscillations seen in OCP curves for TNT formed in ethylene glycol electrolyte confirm ongoing oxidation and metastable nature of nanotubular oxide layers [29]. Annealing in argon causes the increase in the $\mathrm{OCP}$ value $\left(\mathrm{E}_{\mathrm{OCP}}=55.1 \pm 4.2 \mathrm{mV}\right)$ for Ti/TNT layers compared to the OCP value for non-annealed samples $\left(\mathrm{E}_{\mathrm{OCP}}=-220.1 \pm 12.1 \mathrm{mV}\right)$. The contact angle measurements (WCA) carried out on the annealed samples for doubly ionized (DI) water confirmed that all obtained surface layers are hydrophilic. The value of the contact angle presented in Figure 2 for the non-annealed $\mathrm{TiO}_{2}$ nanotubes, which amounts to $20^{\circ} \pm 2^{\circ}$ after annealing in argon, drops to $80^{\circ} \pm 5^{\circ}$.

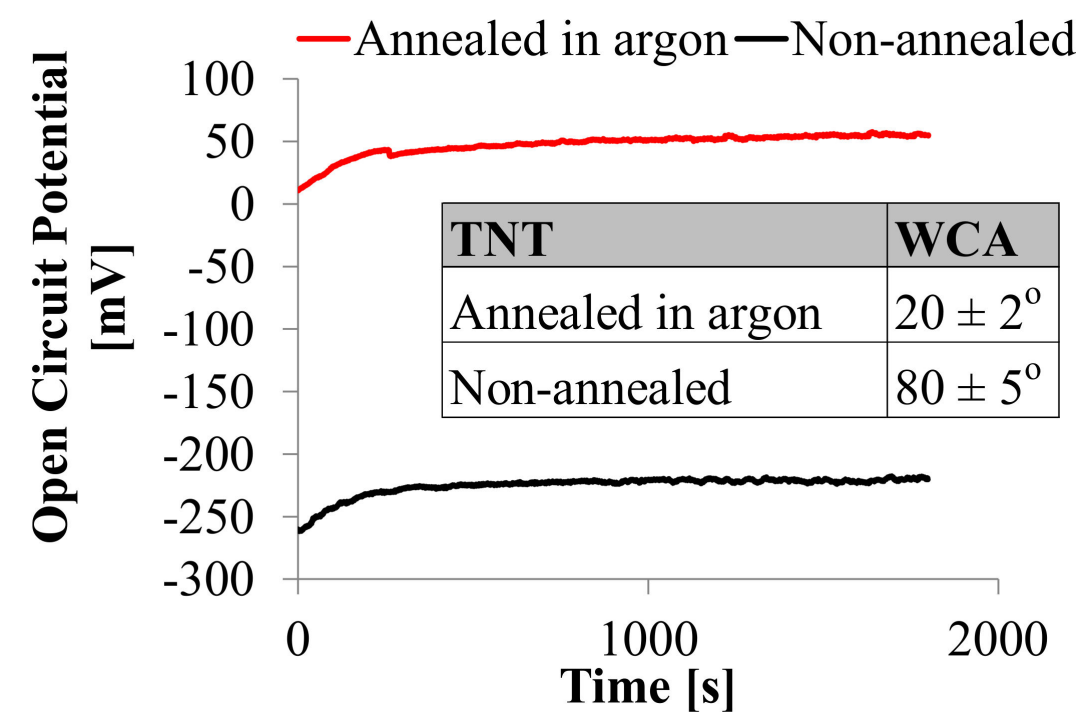

Figure 2. Water contact angle (WCA) and open circuit potential (OCP) measurements of TNT layers (diameter $50 \pm 5 \mathrm{~nm}, 1000 \pm 100 \mathrm{~nm}$ thickness) before and after annealing in argon in temperature $550{ }^{\circ} \mathrm{C}$ for $2 \mathrm{~h}$. 
Anodic titania oxides exhibit semiconductive properties attributed to defects: oxygen vacancies, $\mathrm{Ti}^{3+}$ interstitials, and solvent components and impurities. TNT's conductive properties may be improved by annealing in controlled atmospheres, which causes the semiconductor material to obtain sufficiently higher electronic and ionic conductivity and improve wettability [33]. More positive values of the open circuit potential are favorable for the protein immobilization on the TNT platform, according to the amino acid residues (e.g., HRP) and human antibodies exhibiting negative charges in PBS (0.01 M, $50 \mathrm{~mL}, \mathrm{pH} 7.4)$. The negatively charged protein is easily attached to the biosensor's positive matrix by direct physisorption, resulting from weak electrostatic or van der Waals interaction [54]. The material characterized by WCA values near $90^{\circ}$ can affect hydrophobicity and hydrophilicity, which is favorable for the immobilization process. Protein adsorption is stronger on the hydrophobic surface, but hydrophilic material avoids the protein decomposition [55].

The surface topography, electrical, and adsorption properties of titanium nanotubes (TNT) are important factors for the successful immobilization of biological substances. However, chemical modification of a TNT platform using currently available methods (i.e., silanization) often results in the effective immobilization process via covalent binding. Still, this makes the manufacturing of biosensor time-consuming and costly.

Recently, direct immobilization on the TNT surface was confirmed for the chemical compounds that exist as a cation in aqueous solutions [56]. Physisorption by the electrostatic forces of human antibodies onto the TNT surface, taking into account the values of the isoelectric point of human antibodies, requires the surface charge's positive value. Most biological substances have an isoelectric point lower than 7.4, which results in anions formed in human plasma and serum. Therefore, the immobilization of enzymes and proteins on the surface of TNT requires the presence of mediators [57,58]. Physisorption by the electrostatic forces of human antibodies onto the TNT surface, taking into account the values of the isoelectric point of human antibodies, requires the surface charge's positive value. The surface treatment was performed before the immobilization process to change TNT's surface charge from negative to positive.

\subsection{IL-6, IL-8, TNF $\alpha$ Antibodies Adsorption}

Cyclic voltammetry (CV) studies of TNT and Ab/TNT electrodes in the PBS solution without any external mediator are shown in Figure 3.

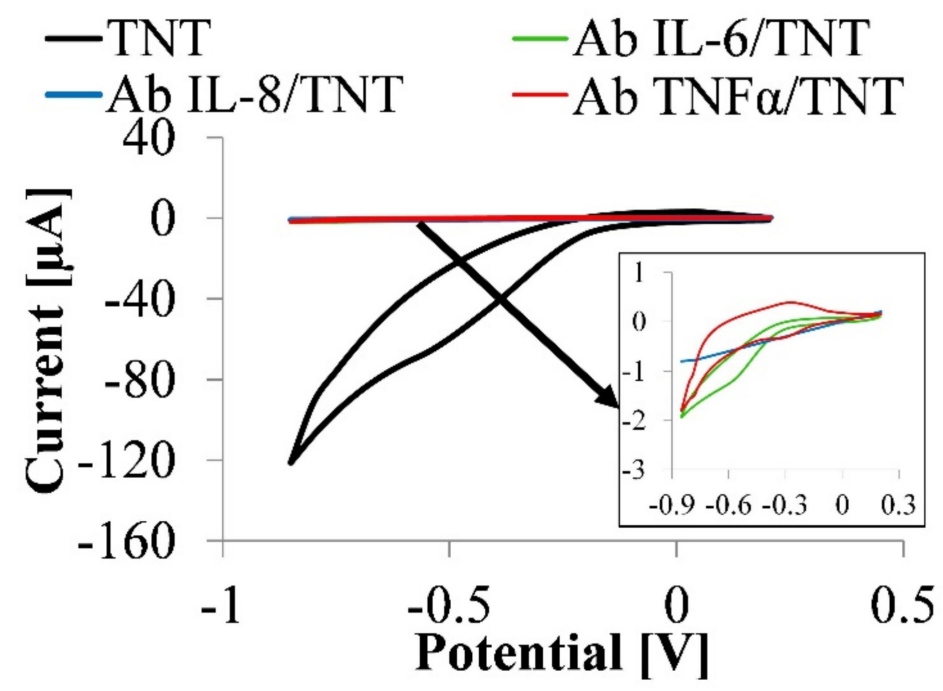

Figure 3. CV curves obtained for the TNT electrode and Ab IL-6, IL-8, TNF $\alpha$ immunoelectrode in $0.01 \mathrm{M}$ PBS solution without any external mediator. 
It is important to note that the bare TNT platform does not show any redox peak, which is related to the fact that TNT does not have any redox couple for the electron transfer from the reaction site to the electrode. Flat cyclic voltammograms confirm the platform's stability in the electrolyte and the lack of redox reaction on TNT's surface. TNT annealed in argon indicates higher current values that prove TNT's high conductivity and provides a fast electron transfer path.

It is clearly seen that the current response serially decreases (Ab IL-6, IL-8, TNF $\alpha$ ) when the electrode is modified with antibodies, as seen in Figure 3. This might be attributed to the insulating $\mathrm{Ab}$ protein layers on the electrode, which would hinder the electron transfers. This is related to the fact that the macromolecules of Ab IL-6, IL-8, TNF $\alpha$ restrict the flow of charge carriers. The results indicated that the immunosensing substrate had formed successfully and could be used in the proposed immunoassay.

After understanding the surface charge of TNT, IL-6, IL-8, TNF $\alpha$ antibodies, adsorption was studied. The direct immobilization of IL-6, IL-8, and TNF $\alpha$ antibodies on the TNT surface was performed by the drop technique for $60 \mathrm{~min}$. The shortest time and the immobilization efficiency (\% of the antibodies attached to the platform surface) were evaluated based on the spectrophotometric analysis of the slopes on every stage of the immobilization process.

According to ELISA tests, immobilization time was defined as $60 \mathrm{~min}$ for each antibody, $120 \mathrm{~min}$ for TNF $\alpha$ antigens, and 150 min for IL-6 and IL- 8 antigens. The average value of the immobilization efficiency of IL-6, IL-8, TNF $\alpha$ immobilization onto TNT's surface was $87.5 \%$ (Figure $4 \mathrm{a}$ ), and for IL-6, IL-8, TNF $\alpha$ antigens was $83.1 \%$. This proves the high physical affinity of IL-6, IL-8, TNF $\alpha$ to the prepared platform covered with TNT and confirms TNT's suitability for effective protein immobilization and biosensing.
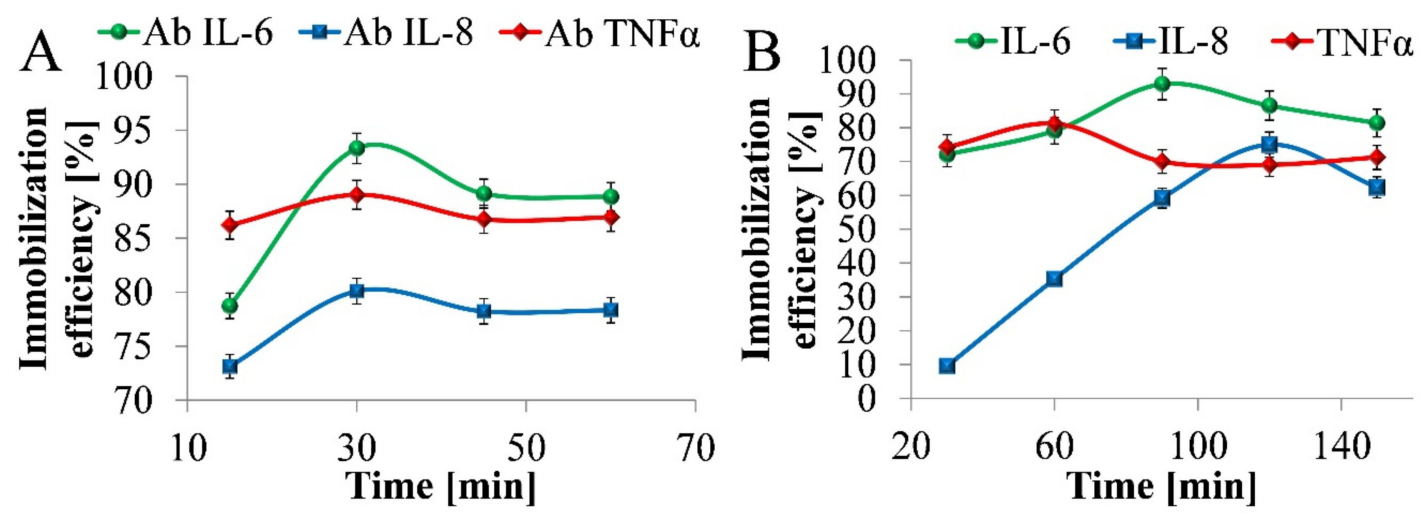

Figure 4. Immobilization efficiency of (A) IL-6, IL-8, TNF $\alpha$ antibodies, and (B) IL-6, IL-8, TNF $\alpha$ antigen on TNT.

For each cytokine, the shortest antibody immobilization time was defined as 30 min and the shortest antigen immobilization time as 90, 120, and $60 \mathrm{~min}$ for IL-6, IL-8, and TNF $\alpha$, respectively. This period was considered sufficient for the effective binding of biomolecules to the TNT matrix based on the performed measurements.

\subsection{Label-Free Detection of IL-6, IL-8, TNF $\alpha$ using Electrochemical Impedance Spectroscopy}

The impedimetric response of the TNT layer (diameter of $50 \pm 5 \mathrm{~nm}$, the height of $1000 \pm 100 \mathrm{~nm}$ ) annealed in argon, immobilized with IL-6, IL-8 and TNF $\alpha$ antibody on the varying concentration of IL-6, IL-8, and TNF $\alpha$ antigens, were analyzed using EIS measurements carried out in the frequency range $10^{5} \div 0.10 \mathrm{~Hz}$ in PBS $(0.01 \mathrm{M}, \mathrm{pH} 7.4)$ solution (Appendix A). An example of Nyquist and Bode plots for the determination of IL-6, IL-8, and TNF $\alpha$ are shown in Figure A1 (Appendix A), including the statistical analysis of performed measurements (Table A1), whereas the calibration curves are presented in Figure 5. 


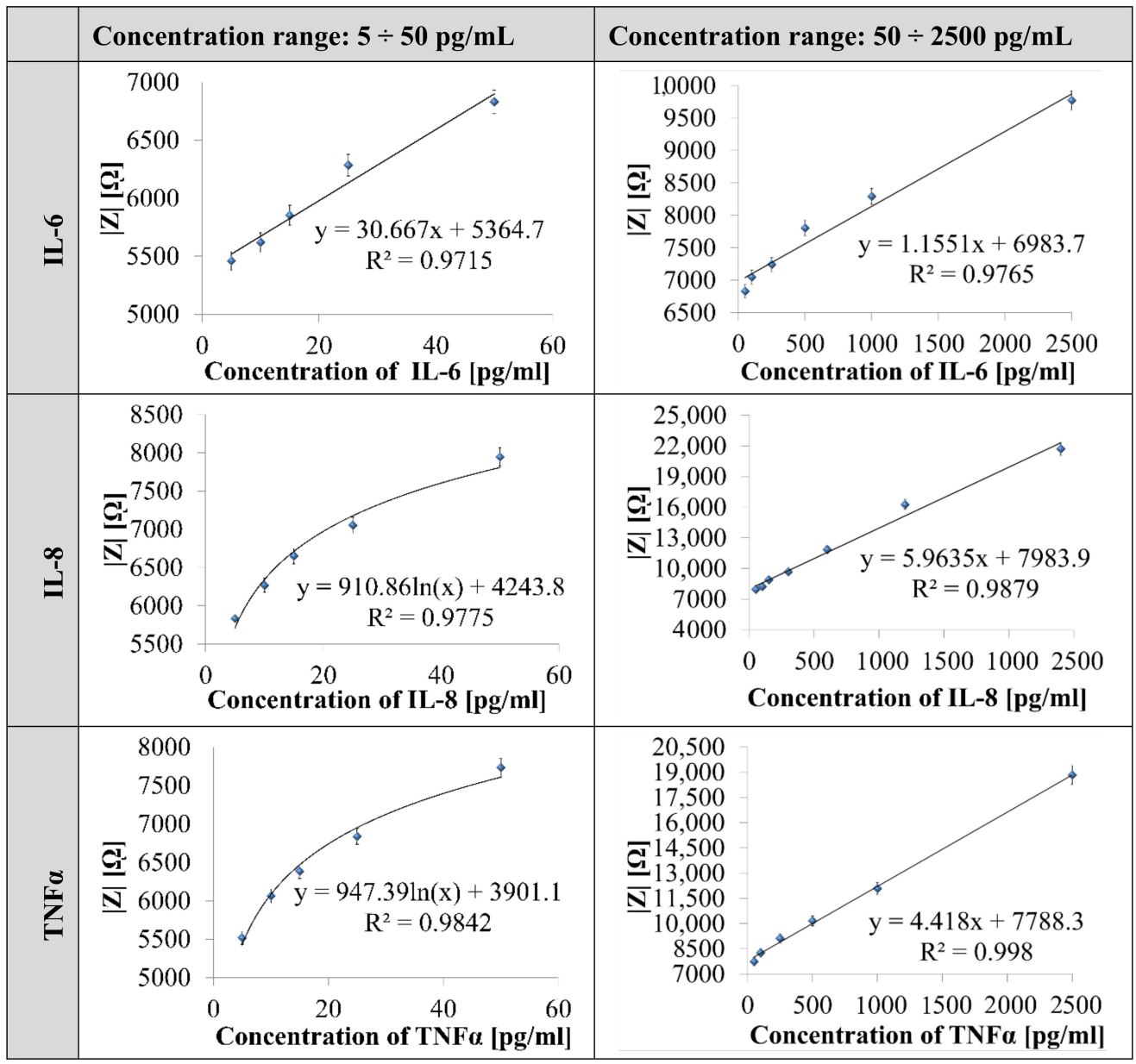

Figure 5. Calibration curve obtained between $|Z|$ and concentration of IL-6, IL-8, and TNF $\alpha$ measured in $0.1 \mathrm{~Hz}$ frequency.

Impedance biosensor responses for IL-6, IL-8, and TNF $\alpha$ are presented in the form of calibration curves (Figure 5), created based on the relationship between the parameters of the impedance characteristics of the biosensors and the concentrations of the determined cytokines.

The calibration curves (Figure 6) show a linear variation in $|Z|$ from $5458 \pm 110 \Omega$ to $9771 \pm 195 \Omega$, from $5831 \pm 115 \Omega$ to $21,706 \pm 430 \Omega$, from $5517 \pm 110 \Omega$ to $18,834 \pm 375 \Omega$ over a wide range of IL-6, IL- 8 and TNF $\alpha$ concentration (5-2500 pg/mL), respectively. The straight line is fitted to the data by linear regression analysis defined by the equations with a regression coefficient (R2), shown in each graph. The regression coefficient values are close to 1 , indicating good linearity of the calibration curve.

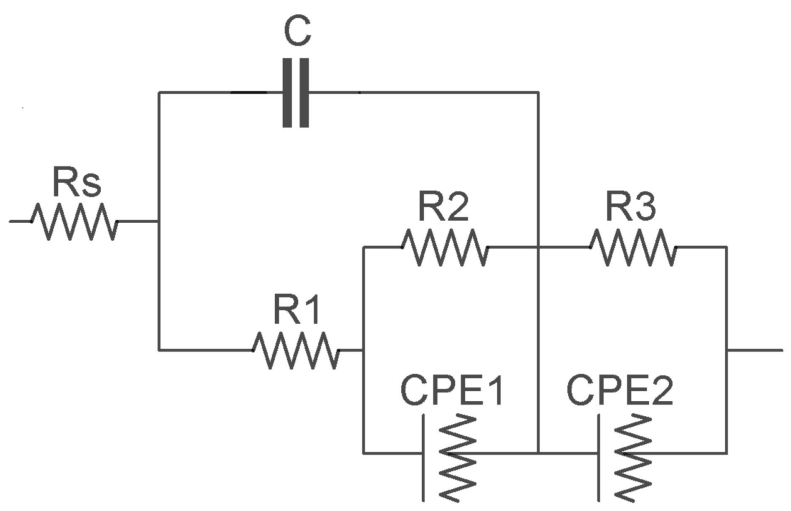

Figure 6. Equivalent circuit for fitting the plots. 
Obtained EIS spectra for TNT/antibody/antigen for the assumed range of concentrations of IL-6, IL-8, TNF $\alpha$ were fitted to the equivalent circuit using Nova 1.8 software. The circuit characterized by the best fit (based on the results of mean square errors $\times 2$ of matching the equivalent circuit using the nonlinear least-squares method) was the one whose graphical form is shown in Figure 6, where Rs-electrolyte resistance; R1—resistance of the porous/nanotubular layer; R2-resistance of the ionic interface between the double layer and the solution; R3-resistance of the biological layer; C1—capacitance of the porous/nanotubular layer; CPE1—double-layer capacitance; CPE2-capacitance of the biological layer.

The obtained results confirm the correlation between the determined cytokine concentration and the parameters of the replacement system (Table 2). As the concentration of human IL-6 increases the electrolyte resistance (Rs) increases, the resistance of the porous layer (R1) increases, and the capacity of the biological layer (CPE2) increases. As the concentration of human IL-8 increases the resistance of the porous layer (R1) increases, the capacity of the porous layer (CPE1) decreases, and surface heterogeneity and roughness $(\alpha 1)$ increase. With the increase in the concentration of human TNF $\alpha$ the resistance of the electrolyte (Rs) increases, the resistance of the double layer (R2) increases, and surface heterogeneity and roughness $(\alpha 1)$ increase.

\subsection{Effect of $p H$ of Electrolyte on IL-6, IL-8, TNF $\alpha$ Biosensor Response}

The effect of $\mathrm{pH}$ on the impedance biosensor response was investigated for the IL-6, IL- 8 , and TNF $\alpha$ antigens at $300 \mathrm{pg} / \mathrm{mL}$ concentrations. Measurements were made in the range from 105 to $0.10 \mathrm{~Hz}$, using the amplitude of the excitation signal of $10 \mathrm{mV}$, in $5 \mathrm{~mL}$ of $0.01 \mathrm{M}$ PBS solution with the following pH values: $2.0 ; 3.0 ; 4.0 ; 5.0 ; 6.0 ; 7.0 ; 7.27 .4 ; 7.6 ; 7.8$, at a temperature of $25{ }^{\circ} \mathrm{C}$. The measurements were carried out with at least three-fold repeatability. The curves showing the dependence of the impedance value (biosensor response) on the analyte's pH are shown in Figure 7.

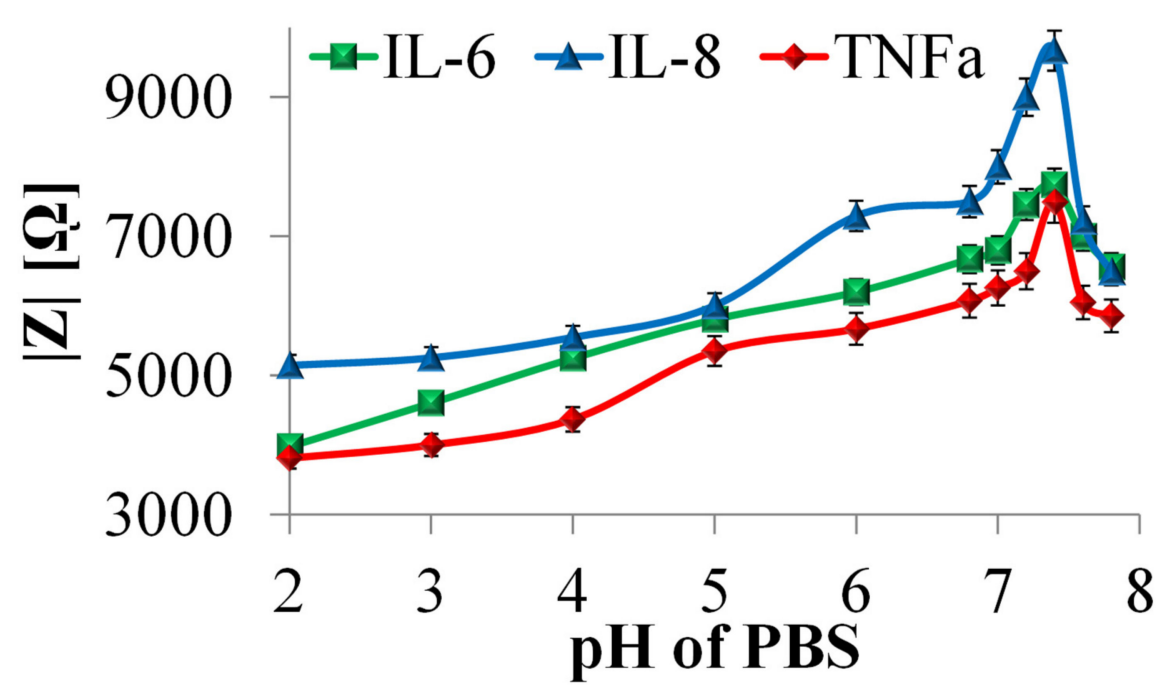

Figure 7. Influence of electrolyte $\mathrm{pH}$ on the value of the impedance modulus measured at the frequency of $0.1 \mathrm{~Hz}$ of the impedance biosensor IL-6, IL- 8 and TNF $\alpha$, recorded in a $0.01 \mathrm{M}$ PBS solution, using the amplitude of the excitation signal of $10 \mathrm{mV}$.

The curves illustrating the influence of $\mathrm{pH}$ electrolyte on the impedimetric biosensor response have a similar course for determining cytokines. In the range of $\mathrm{pH} 2 \div 7.4$ for IL-6, IL- 8 , and TNF $\alpha$, it was observed that increasing the $\mathrm{pH}$ electrolyte results in an increase in the impedance modulus $|\mathrm{Z}|$ measured in the frequency of $0.1 \mathrm{~Hz}$. For each of the determined cytokines, the maximum biosensor response was recorded in an electrolyte at $\mathrm{pH}$ values of 7.4, which is analogous to human plasma $\mathrm{pH}$. The increase in biosensor response observed in the $\mathrm{pH}$ ranges from 6.8 to 7.4 is consistent with literature reports concerning the stability of the antigen-antibody complex and cytokine activity $[59,60]$. 
Reverberi and Ward's research showed that, in the $\mathrm{pH}$ range of 6.8-7.4, with increasing $\mathrm{pH}$ value, the stability of the antigen-antibody bond increases, and biological substance activity increases. Above the $\mathrm{pH}$ value of 7.4, a decrease in the value of the impedance modulus was observed, which may be due to the increase in the number of $\mathrm{Na}^{+}$ions from the PBS alkalizing reagent. This factor has a destabilizing effect on the conformational structure of proteins and prevents antigen-antibody complex formation.

Table 2. Values of equivalent circuit elements obtained for fitting of the experimental data for various concentrations of IL-6, IL-8, TNF $\alpha$ : $\mathrm{R}^{2}$-mean square error; R1-resistance of the porous layer; R2-resistance of the ionic interface between the double layer and the solution; CPE1-double-layer capacitance; $\mathrm{N} 1-n$-value of a CPE1.

\begin{tabular}{|c|c|c|c|c|}
\hline IL-6 (pg/mL) & $x^{2}$ & Rs $(\Omega \iota)$ & R1 $(\Omega \iota)$ & CPE2 (Mho) \\
\hline 0 & 0.025 & 33.5 & 427.4 & $7.54 \times 10^{-9}$ \\
\hline 5 & 0.077 & 39.8 & 319.7 & $5.22 \times 10^{-9}$ \\
\hline 10 & 0.022 & 54.2 & 49.9 & $4.46 \times 10^{-9}$ \\
\hline 25 & 0.049 & 57.8 & 13.9 & $2.37 \times 10^{-6}$ \\
\hline 50 & 0.016 & 68.1 & 2.5 & $3.43 \times 10^{-4}$ \\
\hline 100 & 0.043 & 80.6 & 11.5 & $2.35 \times 10^{-4}$ \\
\hline 250 & 0.092 & 100.9 & 189.2 & $2.25 \times 10^{-4}$ \\
\hline 500 & 0.094 & 110.6 & $1.10 \times 10^{12}$ & $1.80 \times 10^{-3}$ \\
\hline 1000 & 0.050 & 117.1 & $1.10 \times 10^{12}$ & 0.67 \\
\hline 2500 & 0.040 & 140.4 & $1.10 \times 10^{12}$ & 4.71 \\
\hline IL-8 (pg/mL) & $x^{2}$ & R1 $(\Omega \imath)$ & CPE1 (Mho) $\times 10^{-4}$ & $\alpha 1$ \\
\hline 0 & 0.025 & 54.8 & 3.1 & 0.439 \\
\hline 5 & 0.020 & 83.6 & 2.8 & 0.772 \\
\hline 10 & 0.026 & 88.4 & 2.7 & 0.783 \\
\hline 25 & 0.097 & 110.9 & 1.7 & 0.797 \\
\hline 50 & 0.044 & 113.8 & 1.3 & 0.820 \\
\hline 100 & 0.026 & 118.4 & 1.2 & 0.827 \\
\hline 150 & 0.087 & 308.1 & 0.14 & 0.834 \\
\hline 300 & 0.093 & 332.7 & 0.15 & 0.838 \\
\hline 600 & 0.041 & 474.9 & 0.0086 & 0.863 \\
\hline 1200 & 0.016 & 631.1 & 0.0088 & 0.885 \\
\hline 2500 & 0.046 & 27,553 & 0.00026 & 0.974 \\
\hline $\mathrm{TNF} \alpha(\mathrm{pg} / \mathrm{mL})$ & $x^{2}$ & Rs $(\Omega \imath)$ & $\mathrm{R} 2(\Omega \imath)$ & $\alpha 1$ \\
\hline 0 & 0.056 & 28.1 & 3.18 & 0.765 \\
\hline 5 & 0.019 & 55.9 & 70.4 & 0.780 \\
\hline 10 & 0.094 & 73.6 & 72.8 & 0.792 \\
\hline 25 & 0.053 & 91.9 & 91.3 & 0.837 \\
\hline 50 & 0.026 & 101.9 & 103.1 & 0.860 \\
\hline 100 & 0.035 & 108.6 & 152.0 & 0.863 \\
\hline 250 & 0.015 & 123.4 & 181.4 & 0.871 \\
\hline 500 & 0.064 & 140.5 & 247.4 & 0.899 \\
\hline 1000 & 0.014 & 196.4 & 8511.0 & 0.980 \\
\hline 2500 & 0.047 & 272.4 & $17,332.0$ & 0.987 \\
\hline
\end{tabular}

The nature of the dependence of the impedance biosensor response for the detection of IL-6, IL-8, and TNF $\alpha$ concentrations on the $\mathrm{pH}$ of the analyte confirms both the sensitivity of the biosensor to a change in analyte $\mathrm{pH}$ and the broad spectrum of activity of the analyzed substances and their ability to form antigen-antibody complexes. Considering the potential use of a biosensor to measure cytokine concentration in human plasma, it is advantageous to achieve a maximal biosensor response for an analyte $\mathrm{pH}$ corresponding to human plasma.

The detection of selected markers with the use of biosensors, described in the literature (Table 3), is a long-term process due to the multi-stage nature of its preparation [1-14]. The presented biosensors 
require the use of additional surface functionalization processes, such as silanization [3], surface modification with EDC/NHS [6-8,12], Merkapto [8], APTES [4,9], or marking antibodies with biotin/streptavidin $[9,13,14]$. In addition, the immobilization time of antibodies is equal to night $[1,2]$, 12 [10], 6 [3], 5 [12], 4 [4], and $3 \mathrm{~h} \mathrm{[6,9],} \mathrm{and} \mathrm{antigens} 6$ [3] and $2 \mathrm{~h} \mathrm{[14].} \mathrm{The} \mathrm{titanium} \mathrm{dioxide} \mathrm{nanotube}$ biosensor described in the manuscript does not require the use of additional surface modification processes, which allows for a faster electrode preparation process. Additionally important is the short time (60 $\mathrm{min}$ ) immobilization of both antibodies and antigens IL-6, IL-8, and TNF $\alpha$.

Table 3. Properties of different types of biosensor for detection of IL-6, IL-8, and TNF $\alpha$.

\begin{tabular}{|c|c|c|c|c|c|}
\hline Target & $\begin{array}{l}\text { Composition of Sensitive } \\
\text { Film }\end{array}$ & Detection Method & $\begin{array}{c}\text { Limit of } \\
\text { Detection }\end{array}$ & Linear Range & Ref. \\
\hline \multirow{12}{*}{ IL-6 } & $\mathrm{Au}$ rods $/ \mathrm{Ab}^{1}$ & Potentiometric & $10 \mathrm{ng} / \mathrm{mL}$ & - & [10] \\
\hline & $\begin{array}{l}\text { APCPG/CC/Ab/Ag/Ab1- } \\
\text { Strepravidin-alkaline }\end{array}$ & Amperometric & $0.41 \mathrm{pg} / \mathrm{mL}$ & $0 \div 400 \mathrm{pg} / \mathrm{mL}$ & [11] \\
\hline & $\mathrm{ZnO} / \mathrm{SiO}_{2} / \mathrm{Si}-\mathrm{Ab}$ & SAW & - & $20 \mathrm{ng} / \mathrm{mL} \div 2 \mu \mathrm{g} / \mathrm{mL}$ & [12] \\
\hline & $\begin{array}{l}\text { Combination tapered } \\
\text { fiber-optic biosensor } \\
\text { (CTFOB)/Ab }\end{array}$ & Optic & $0.12 \mathrm{ng} / \mathrm{mL}$ & $40 \mathrm{pg} / \mathrm{mL} \div 100 \mathrm{ng} / \mathrm{mL}$ & [13] \\
\hline & SWCT-Ab1/Ag/Ab2-HRP & Amperometric & $0.05 \mathrm{pg} / \mathrm{mL}$ & $0.5 \div 5 \mathrm{pg} / \mathrm{mL}$ & [14] \\
\hline & $\begin{array}{c}\text { ITO/AuNP/PDOP } \\
\text { Poly-dopamine } \\
\text {-Ab-Ag-Ab1-HRP/Ab2/CNT }\end{array}$ & Amperometric & $1 \mathrm{pg} / \mathrm{mL}$ & $4 \div 800 \mathrm{pg} / \mathrm{mL}$ & [15] \\
\hline & $\begin{array}{l}\text { SWCNTforests-Ab1/Ag/Ab2- } \\
\mathrm{Ru}(\mathrm{bpy})_{3}{ }^{2+} \text {-silica }\end{array}$ & ECL & $0.25 \mathrm{pg} / \mathrm{mL}$ & - & [16] \\
\hline & Au-Ab1/Ag/Ab2-Poly-HRP & Amperometric & $10 \mathrm{fg} / \mathrm{mL}$ & $10 \div 1300 \mathrm{fg} / \mathrm{mL}$ & [17] \\
\hline & $\begin{array}{l}\text { Magnetic-photocatalytic } \\
\text { hybrid nanoparticles with } \\
\text { a highly crystalline } \mathrm{TiO}_{2} \\
\text { shell-Ab }\end{array}$ & Microresonators & $0.1 \mathrm{pg} / \mathrm{mL}$ & - & [18] \\
\hline & $\mathrm{SiO}_{2} / \mathrm{Si} / \mathrm{CNT} / \mathrm{AuNP}-\mathrm{Ab}$ & Impedimetric & $0.01 \mathrm{fg} / \mathrm{mL}$ & $0.01 \div 100 \mathrm{fg} / \mathrm{ml}$ & [19] \\
\hline & SWCNT-Ab & FET & $1.37 \mathrm{pg} / \mathrm{mL}$ & - & [20] \\
\hline & $\mathrm{CNT} / \mathrm{AuNP}-\mathrm{Ab}$ & Impedimetric & $0.01 \mathrm{fg} / \mathrm{mL}$ & $0.00001 \div 0.1 \mathrm{pg} / \mathrm{mL}$ & {$[21]$} \\
\hline \multirow{3}{*}{ IL-8 } & $\begin{array}{c}\text { PEG/Au/non-antibody } \\
\text { capture proteinbased on a } \\
\text { cystatin scaffold }\end{array}$ & Impedimetric & $90 \mathrm{fg} / \mathrm{mL}$ & $900 \mathrm{fg} / \mathrm{mL} \div 900 \mathrm{ng} / \mathrm{mL}$ & [22] \\
\hline & $\begin{array}{l}\text { ELISA surface with } \\
\text { capture probe }\end{array}$ & Optical & $32 \mathrm{fg} / \mathrm{mL}$ & $5 \mathrm{fg} / \mathrm{mL} \div 1 \mathrm{pg} / \mathrm{mL}$ & [23] \\
\hline & Polysilicon nanowire-Ab & - & $80 \mathrm{fg} / \mathrm{mL}$ & - & {$[24]$} \\
\hline \multirow{3}{*}{$\mathrm{TNF} \alpha$} & $\begin{array}{c}\text { Dendrimer-based } \\
\text { PEG/Ab/Ag/Ab2-HRP }\end{array}$ & Optical & $0.48 \mathrm{pg} / \mathrm{mL}$ & $0 \div 300 \mathrm{pg} / \mathrm{mL}$ & [25] \\
\hline & MB labeled TNF $\alpha$ aptamer & Optical & $10 \mathrm{ng} / \mathrm{mL}$ & $10 \div 100 \mathrm{ng} / \mathrm{mL}$ & [26] \\
\hline & $\begin{array}{l}\text { Au-Si-dithiobis-succinimidyl } \\
\text { propionate }\end{array}$ & Impedimetric & $1 \mathrm{pg} / \mathrm{mL}$ & $1 \mathrm{pg} / \mathrm{mL} \div 1 \mathrm{ng} / \mathrm{mL}$ & [27] \\
\hline
\end{tabular}

${ }^{1} \mathrm{Ab}$ - antibody, Ag - antigen, APCPG - 3-aminopropyl-modified controlled-pore glass, CC - central channel, MB - Methylene Blue, HRP -Horseradish Peroxidase, Au- gold, AuNP - gold nanoparticles, SWCT - single-well chemical tracer, CNT - carbon nanotubes, PEG - Poly(ethylene glycol), SAW - Surface acoustic wave, ECL Electrochemiluminescence method, FET - Field-Effect Transistor.

\section{Conclusions}

The development of an efficient electrochemical immunosensor to detect IL-6, IL-8, and TNF $\alpha$ using TNT has been successfully demonstrated. The thermal modification of TNT (diameter: $50 \pm 5 \mathrm{~nm}$, height: $1000 \pm 100 \mathrm{~nm}$ ) in argon atmosphere results in a change in the value of open circuit potential from negative to positive, increasing the resistive character and decreasing the nonhomogeneity. The successful immobilization of the antibody of IL-6, IL-8, and TNF $\alpha$ onto the TNT surface via physisorption was carried out for $30 \mathrm{~min}$, which is a much shorter time than currently available analytical methods. 
The high sensitivity of the prepared substrates to $\mathrm{pH}$ changes was observed in impedimetric tests, and the highest impedance modulus values were measured in the analyte at $\mathrm{pH}$ 7.4. The obtained results indicate that the tested cytokine antibodies and antigens are not inactivated in a wide $\mathrm{pH}$ range, which ensures the universality of the biosensors being developed.

Calibration curves of impedance biosensors for each of the determined cytokines showed that the detection limits for IL-8, IL-6, TNF $\alpha$ are 192, 625, and $295 \mathrm{fM}$, respectively, which correspond to physiological norms, where the detection range covers clinically important concentrations from 5 to $2500 \mathrm{pg} / \mathrm{mL}$.

Author Contributions: Data curation, K.A.; formal analysis, K.A.; investigation, K.A.; methodology, K.A.; supervision, K.A.; writing-original draft, E.P. and K.A.; writing-review and editing, E.P. and K.A. All authors have read and agreed to the published version of the manuscript.

Funding: K.A. and E.P. acknowledge the financial support from the program of the Polish Minister of Science and Higher Education under the name "Regional Initiative of Excellence" in 2019-2022, project no. 003/RID/2018/19, funding amount 11936 596.10 PLN.

Conflicts of Interest: The authors declare no conflict of interest.

\section{Appendix A}

The impedimetric response of TNT layer (diameter of $50 \pm 5 \mathrm{~nm}$, the height of $1000 \pm 100 \mathrm{~nm}$ ) annealed in argon, immobilized with IL-6, IL-8 and TNF $\alpha$ antibody on the varying concentration of IL-6, IL-8, and TNF $\alpha$ antigens were analyzed using EIS measurements carried out in frequency range $10^{5} \div 0.10 \mathrm{~Hz}$ in PBS $(0.01 \mathrm{M}, \mathrm{pH} 7,4)$ solution. An example of Nyquist and Bode plots for the determination of IL-6, IL-8, and TNF $\alpha$ were shown in Figure A1. Each measurement was performed with a minimum of 3-times repeatability. To calculated the values of standard deviation (SD) relative standard deviation (RSD) for electrochemical parameter (EIS) the equations were used accordingly (1), (2) where $\mathrm{Xi}$ - each of the values of the data for 3 samples, $\mathrm{X}$ - the mean of $\mathrm{Xi}, \mathrm{n}$ - the number of data points equal to 3 . The results of statistical analysis were shown in Table A1.

$$
\begin{gathered}
S D=\sqrt{\frac{\sum_{i=1}^{n}(X i-X)^{2}}{n-1}} \\
R S D=\frac{S D}{X}
\end{gathered}
$$

The phase shift angle values recorded at the lowest frequency $(0.1 \mathrm{~Hz})$ presented in Bode's graphs (Figure A1) range from $50^{\circ}$ to $90^{\circ}$ for each of the determined cytokines (Table A1). Correlations between its values (measured at a frequency of $0.1 \mathrm{~Hz}$ ) and the determined IL- 8 antigen concentrations were observed (Figure A1B). With the increase in the concentration of the determined cytokine, the value of the phase angle decreases. Along with the increase in the concentrations of antigens: IL- 8 and TNF $\alpha$, the phase angle values for the frequency of $0.1 \mathrm{~Hz}$ decrease, which proves that the heterogeneity of the TNT surface decreases due to combining the antigen with antibodies immobilized on the surface of TNT. Forming antigen-antibody complexes, filling the pores, reduce its porosity.

Data illustrating changes in the phase angle (Table A1) for high concentrations of the determined cytokines IL-6, IL-8 and TNF $\alpha$ (concentrations greater than 250 pg/mL for Il-6, 600 pg/mL for IL-8, and $1000 \mathrm{pg} / \mathrm{mL}$ for $\mathrm{TNF} \alpha$ ) indicate the existence of two-time constants, which proves the presence of two layers on the electrode surface: the first is the layer of immobilized antibody, the second is the layer of antibody-antigen complexes. Greater heterogeneity (porosity) the surface layer for lower concentrations may result from incomplete antibody layer coverage with antigens. As antigens increase and more antibody-antigen complexes form, it decreases the value of the phase angle determines the layer's non-uniformity, and its value measured at high frequency $\left(10^{5} \mathrm{~Hz}\right)$ is also lowered, corresponding to the resistance of the electrolyte penetrating the porous electrode surface. The served increasing values of the phase angle for the time constant in the frequency range from 10 to $50 \mathrm{~Hz}$ well 
illustrate its dependence on the increasing concentration of the antigen. It is also confirmed by the correlation between the phase angle values and different concentrations of IL-6 in the studied range.

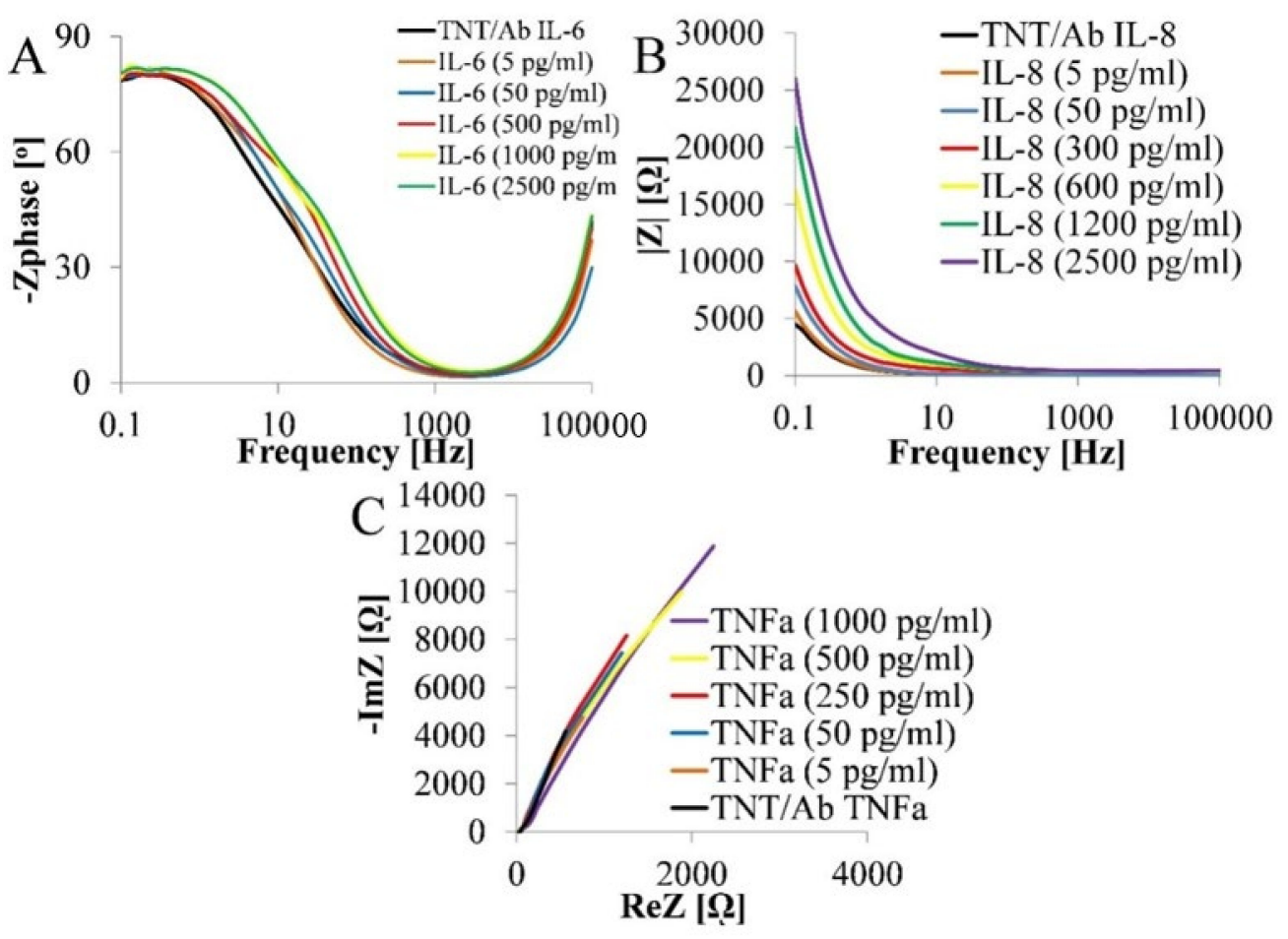

Figure A1. Impedimetric response studies of TNT immunoelectrode incubated with different concentration of IL-6, IL-8, TNF $\alpha$, presented in Bode representations for IL-6 (A) and IL-8 (B) and in Nyquist representation for $\mathrm{TNF} \alpha(\mathbf{C})$.

The curves showing the dependence of the impedance modulus on frequency for different cytokines concentrations: IL-6, IL-8 (Figure 1B), and TNF $\alpha$ are similar. The impedance modulus values recorded at the lowest frequency of $0.1 \mathrm{~Hz}$ are in the range from 3000 to $25,000 \Omega$ for the determined cytokines (Table A1). The lowest value of the impedance modulus $\left(\sim 3 \times 10^{3} \Omega\right)$ was recorded for the TNT layer with a diameter of $50 \mathrm{~nm}$, height $1000 \mathrm{~nm}$, annealed in argon, and not functionalized. For each of the determined cytokines, an increase in the impedance modulus's value was observed with the increase in their concentration. This means that as the TNT layer is coated with antibodies and then with increasing antigens concentrations, which results in the formation of antigen-antibody complexes, the impedance modulus of the test layer increases. This tendency corresponds to the characteristics of biological systems covering the electrodes [58].

Nyquist curves of TNT with IL-6, IL-8, and TNF $\alpha$ (Figure A1C) antibodies immobilized on its surface, similarly to before immobilization, have the shape of large semi-circles - characteristic of thin oxide layers. With the increase in the concentration of IL-6, IL-8, TNF $\alpha$, the angle of the curves and the radius of the circles decreased, which indicates a decrease in the charge exchange resistance in the presence of an increasing number of antigen-antibody bonds. Their presence on the biosensor electrode's surface may stimulate the exchange of electrons, causing an increase in the electrical conductivity of the layer, thus reducing its resistance. 
Table A1. Results of electrochemical impedance spectroscopy obtained for the varying concentration of IL-6, IL-8, TNF $\alpha$ immunoelectrode measured in 0.01 M PBS solution, where: SD - standard deviation, RSD—relative standard deviation.

\begin{tabular}{|c|c|c|c|c|c|c|c|c|c|c|c|c|}
\hline $\begin{array}{l}\text { Marker conc. } \\
(\mathrm{pg} / \mathrm{mL})\end{array}$ & $|\mathrm{Z}|(\Omega)$ & SD & RSD (\%) & $\operatorname{ReZ}(\Omega)$ & SD & RSD (\%) & $-\operatorname{ImZ}(\Omega)$ & SD & RSD (\%) & -Zphase $\left({ }^{\circ}\right)$ & SD & RSD (\%) \\
\hline \multicolumn{13}{|c|}{ IL-6 } \\
\hline $\mathrm{TNT} / \mathrm{Ab}$ & 5567 & 52 & 0.9 & 1100 & 53 & 4.8 & 5457 & 93 & 1.7 & 27 & 1.4 & 5.1 \\
\hline 5 & 5459 & 86 & 1.6 & 960 & 68 & 7.1 & 5374 & 84 & 1.6 & 28 & 1.3 & 4.6 \\
\hline 10 & 5618 & 83 & 1.5 & 954 & 74 & 7.8 & 5536 & 74 & 1.3 & 30 & 1.9 & 6.3 \\
\hline 25 & 6684 & 64 & 1.0 & 1256 & 46 & 3.7 & 6667 & 65 & 1.0 & 32 & 1.7 & 5.3 \\
\hline 50 & 6830 & 76 & 1.1 & 1333 & 36 & 2.7 & 6699 & 87 & 1.3 & 33 & 1.4 & 4.3 \\
\hline 100 & 7047 & 75 & 1.1 & 1156 & 83 & 7.2 & 6952 & 84 & 1.2 & 36 & 1.8 & 5.0 \\
\hline 250 & 7743 & 92 & 1.2 & 1593 & 109 & 6.8 & 7577 & 62 & 0.8 & 39 & 1.5 & 3.9 \\
\hline 500 & 8203 & 108 & 1.3 & 1372 & 89 & 6.5 & 8087 & 85 & 1.1 & 39 & 1.4 & 3.6 \\
\hline 1000 & 8490 & 120 & 1.4 & 1567 & 77 & 4.9 & 8345 & 58 & 0.7 & 42 & 1.9 & 4.5 \\
\hline 2500 & 9372 & 184 & 2.0 & 1917 & 114 & 5.9 & 9174 & 137 & 1.5 & 44 & 1.4 & 3.2 \\
\hline \multicolumn{13}{|c|}{ IL-8 } \\
\hline TNT/Ab & 4507 & 43 & 1.0 & 822 & 57 & 6.9 & 4432 & 73 & 1.6 & 81 & 1.5 & 1.8 \\
\hline 5 & 5831 & 69 & 1.2 & 1045 & 74 & 7.1 & 6159 & 58 & 0.9 & 79 & 1.9 & 2.4 \\
\hline 10 & 6268 & 71 & 1.1 & 1018 & 56 & 5.5 & 6286 & 83 & 1.3 & 79 & 1.9 & 2.4 \\
\hline 25 & 7051 & 98 & 1.4 & 1273 & 68 & 5.3 & 7253 & 59 & 0.8 & 78 & 1.7 & 2.2 \\
\hline 50 & 7946 & 70 & 0.9 & 1535 & 82 & 5.3 & 7694 & 77 & 1.0 & 71 & 1.5 & 2.1 \\
\hline 100 & 8217 & 94 & 1.1 & 2734 & 95 & 3.5 & 7253 & 85 & 1.2 & 71 & 1.7 & 2.4 \\
\hline 150 & 8884 & 141 & 1.6 & 2881 & 85 & 2.9 & 8403 & 82 & 1.0 & 70 & 1.4 & 2.0 \\
\hline 300 & 9669 & 109 & 1.1 & 3204 & 106 & 3.3 & 9123 & 95 & 1.0 & 69 & 1.9 & 2.7 \\
\hline 600 & 11,839 & 118 & 1.0 & 5576 & 95 & 1.7 & 15,265 & 194 & 1.3 & 69 & 1.8 & 2.6 \\
\hline 1200 & 16,252 & 168 & 1.0 & 9351 & 94 & 1.0 & 19,589 & 184 & 0.9 & 64 & 1.8 & 2.8 \\
\hline 2500 & 21,706 & 182 & 0.8 & 14,594 & 134 & 0.9 & 21,499 & 192 & 0.9 & 56 & 1.8 & 3.2 \\
\hline \multicolumn{13}{|c|}{$\mathrm{TNF} \alpha$} \\
\hline TNT/Ab & 4230 & 73 & 1.7 & 563 & 64 & 11.4 & 4193 & 65 & 1.6 & 82 & 1.8 & 2.2 \\
\hline 5 & 4917 & 85 & 1.7 & 758 & 48 & 6.3 & 4802 & 59 & 1.2 & 79 & 2.1 & 2.7 \\
\hline 10 & 6063 & 69 & 1.1 & 563 & 84 & 14.9 & 5724 & 128 & 2.2 & 80 & 1.9 & 2.4 \\
\hline 25 & 7235 & 92 & 1.3 & 758 & 88 & 11.6 & 6842 & 95 & 1.4 & 80 & 1.8 & 2.2 \\
\hline 50 & 7733 & 108 & 1.4 & 1185 & 92 & 7.8 & 7930 & 45 & 0.6 & 81 & 1.7 & 2.1 \\
\hline 100 & 8253 & 125 & 1.5 & 1202 & 58 & 4.8 & 8157 & 184 & 2.3 & 81 & 2 & 2.5 \\
\hline 250 & 9113 & 144 & 1.6 & 1256 & 93 & 7.4 & 7340 & 182 & 2.5 & 81 & 1.6 & 2.0 \\
\hline 500 & 10,155 & 184 & 1.8 & 1883 & 183 & 9.7 & 9979 & 148 & 1.5 & 79 & 1.9 & 2.4 \\
\hline 1000 & 12,081 & 199 & 1.6 & 2248 & 147 & 6.5 & 11,870 & 157 & 1.3 & 79 & 1.8 & 2.3 \\
\hline 2500 & 18,082 & 176 & 1.0 & 2385 & 193 & 8.1 & 15,853 & 284 & 1.8 & 80 & 1.6 & 2.0 \\
\hline
\end{tabular}

\section{References}

1. Chen, L.; Deng, H.; Cui, H.; Fang, J.; Zuo, Z.; Deng, J.; Li, J.; Wang, X.; Zhao, L. Inflammatory responses and inflammation-associated diseases in organs. Oncotarget 2018, 9, 7204-7218. [CrossRef]

2. Bohmwald, K.; Gálvez, M.S.; Canedo-Marroquín, G.; Pizarro-Ortega, M.S.; Andrade-Parra, C.; Gómez-Santander, F.; Kalergis, A.M. Contribution of Cytokines to Tissue Damage During Human Respiratory Syncytial Virus Infection. Front. Immunol. 2019, 10, 1-10. [CrossRef]

3. Kany, S.; Tilmann, J.; Relja, B. Cytokines in Inflammatory Disease. Int. J. Mol. Sci. 2019, 20, 6008. [CrossRef]

4. Justin, M.; Dominguez, C.; Hamilton, D.; Palena, K. The IL-8/IL-8R Axis: A Double Agent in Tumor Immune Resistance. Vaccines 2016, 4, 22-45.

5. Montfort, A.; Colacios, C.; Levade, T.; Andrieu, A.; Meyer, N.; Ségui, B. The TNF Paradox in Cancer Progression and Immunotherapy. Front. Immunol. 2019, 10, 1818. [CrossRef]

6. Rastogi, P.; Jeyaraman, P.; Sachdeva, M.; Malhotra, P.; Ahluwalia, J. Synchronous hairy cell leukemia and chronic lymphocytic leukemia: A case report with a brief review of literature. Blood Res. 2018, 53, 160-181. [CrossRef]

7. Yang, C.; Brooks, E.; Li, Y.; Denny, P.; Ho, C.; Qi, F.; Shi, W.; Wolinsky, B.; Wu, L.; Wong, D.; et al. Detection of picomolar levels of interleukin-8 in human saliva by SPR. Lab. Chip. 2005, 5, 1017-1023. [CrossRef]

8. Pedersen, L.M.; Schistad, E.; Jacobsen, L.M.; Røe, C.; Gjerstad, J. Serum levels of the pro-inflammatory interleukins 6 (IL-6) and -8 (IL-8) in patients with lumbar radicular pain due to disc herniation: A 12-month prospective study. Brain Behav. Immun. 2015, 46, 132-136. [CrossRef]

9. Khan, M.A.; Mujahid, M. Recent Advances in Electrochemical and Optical Biosensors Designed for Detection of Interleukin 6. Sensors 2020, 20, 646-673. [CrossRef]

10. Berggren, C.; Bjarnason, B.; Johansson, G. An immunological Interleukine-6 capacitive biosensor using perturbation with a potentiostatic step. Biosens. Bioelectron. 1998, 13, 1061-1068. [CrossRef] 
11. German, A.; Messina, G.A.; Panini, V.; Martinez, A.; Raba, J. Microfluidic immunosensor design for the quantification of interleukin-6 in human serum samples. Anal. Biochem. 2008, 380, 262-267.

12. Krishnamoorthy, S.; Iliadis, A.A.; Beic, T.; Chrousos, G.P. An interleukin-6 $\mathrm{ZnO} / \mathrm{SiO}_{2} / \mathrm{Si}$ surface acoustic wave biosensor. Biosens. Bioelectron. 2008, 24, 313-318. [CrossRef]

13. Kapoor, R.; Wang, C.W. Highly specific detection of interleukin-6 (IL-6) protein using combination tapered fiber-optic biosensor dip-probe. Biosens. Bioelectron. 2009, 24, 2696-2701. [CrossRef]

14. Malhotra, R.; Patel, V.; Vaque, J.P.; Gutkind, J.S.; Rusling, J.F. Ultrasensitive electrochemical immunosensor for oral cancer biomarker IL-6 using carbon nanotube forest electrodes and multilabel amplification. Anal. Chem. 2010, 82, 3118. [CrossRef]

15. Wang, G.; Huang, H.; Zhang, G.; Zhang, X.; Fang, B.; Wang, L. Dual Amplification Strategy for the Fabrication of Highly Sensitive Interleukin-6 Amperometric Immunosensor Based on Poly-Dopamine. Langmuir 2011, 27, 1224-1231. [CrossRef]

16. Sardesai, P.; Barron, J.C.; Rusling, J.F. Carbon Nanotube Microwell Array for Sensitive Electrochemiluminescent Detection of Cancer Biomarker Proteins. Anal. Chem. 2011, 83, 6698-6703. [CrossRef]

17. Tang, C.K.; Vaze, A.; Rusling, J.F. Fabrication of immunosensor microwell arrays from gold compact discs for detection of cancer biomarker proteins. Lab Chip 2012, 12, 281-301. [CrossRef]

18. Joo, J.; Kwon, D.; Yim, C.; Jeon, S. Highly Sensitive Diagnostic Assay for the Detection. ACS Nano 2012, 6, 4375-4381. [CrossRef]

19. Wang, G.; He, X.; Chen, L.; Zhu, Y.; Zhang, X. Ultrasensitive IL-6 electrochemical immunosensor based on Au nanoparticles-graphene-silica biointerface. Colloids Surf. B 2014, 116, 714-719. [CrossRef]

20. Chen, H.; Choo, T.K.; Huang, J.; Wang, Y.; Liu, Y.; Platt, M.; Tok, A.I.Y. Label-free electronic detection of interleukin-6 using horizontally aligned carbon nanotubes. Mater. Des. 2016, 90, 852-857. [CrossRef]

21. Yang, T.; Wang, S.; Jin, H.; Bao, W.; Huang, S.; Wang, J. An electrochemical impedance sensor for the label-free ultrasensitive detection of interleukin-6 antigen. Sens. Actuators B Chem. 2013, 178, 310-315. [CrossRef]

22. Sharma, R.; Deacon, S.E.; Nowak, D.; George, S.E.; Szymonik, M.P.; Tang, A.; Tomlinson, D.C.; Davies, A.G.; McPherson, M.J.; Wälti, C. Label-free electrochemical impedance biosensor to detect human interleukin-8 in serum with sub-pg/mL sensitivity. Biosen. Bioelectron. 2016, 80, 607-613. [CrossRef]

23. Winny, T. Optical Protein Sensor for Detecting Cancer Markers in Saliva. Biosens. Bioelectron. 2008, 24, $266-271$.

24. Hakim, M.M.A.; Lombardini, M.; Sun, K.; Giustiniano, F.; Roach, P.L.; Davies, D.E.; Ashburn, P. Thin Film Polycrystalline Silicon Nanowire Biosensors. Nano Lett. 2012, 12, 1868-1872. [CrossRef]

25. Bosnjakovic, A.; Mishra, M.K.; Han, H.J.; Romero, R.; Kannan, R.M. A dendrimer-based immunosensor for improved capture and detection of tumor necrosis factor- $\alpha$ cytokine. Anal. Chim. Acta 2012, 720, 118-125. [CrossRef]

26. Liu, Y.; Zhou, Q.; Revzin, A. An aptasensor for electrochemical detection of tumor necrosis factor in human blood. Analyst 2013, 138, 4321-4326. [CrossRef]

27. Pui, T.S.; Bansal, T.; Kongsuphol, P.; Arya, S.K. Highly Sensitive Label Free Biosensor for Tumor Necrosis Factor. World Acad. Sci. Eng. Technol. 2012, 69, 747-750.

28. Topkaya, S.; Azimzadeh, M.; Ozsoz, M. Electrochemical Biosensors for Cancer Biomarkers Detection: Recent Advances and Challenges. Electroanalysis 2016, 28, 1402-1419. [CrossRef]

29. Arkusz, K.; Paradowska, E.; Nycz, M.; Krasicka-Cydzik, E. Influence of Thermal Modification and Morphology of $\mathrm{TiO}_{2}$ Nanotubes on Their Electrochemical Properties for Biosensors Applications. J. Nano Nanotech. 2018, 18, 3713-3721. [CrossRef]

30. Jafari, S.; Mahyad, B.; Hashemzadeh, H.; Janfaza, S.; Gholikhani, T.; Tayebi, L. Biomedical Applications of $\mathrm{TiO}_{2}$ Nanostructures: Recent Advances. Int. J. Nanomed. 2020, 15, 3447-3470. [CrossRef]

31. Arkusz, K.; Krasicka-Cydzik, E. The effect of phosphates and fluorides, included in $\mathrm{TiO}_{2}$ nanotube layers, on the performance of hydrogen peroxide detection. Archives Metall. Mat. 2018, 63, 765-772.

32. Nycz, M.; Paradowska, E.; Arkusz, K.; Pijanowska, D.G. Influence of geometry and annealing temperature in argon atmosphere of $\mathrm{TiO}_{2}$ nanotubes on their electrochemical properties. Acta Bioeng. Biomech. 2020, 22, 165-177. [CrossRef]

33. Nycz, M.; Arkusz, K.; Pijanowska, D.G. Influence of the Silver Nanoparticles (AgNPs) Formation Conditions onto Titanium Dioxide $\left(\mathrm{TiO}_{2}\right)$ Nanotubes Based Electrodes on Their Impedimetric Response. Nanomaterials 2019, 9, 1-15. [CrossRef] 
34. Paradowska, E.; Arkusz, K.; Pijanowska, D.G. The Influence of the Parameters of a Gold Nanoparticle Deposition Method on Titanium Dioxide Nanotubes, Their Electrochemical Response, and Protein Adsorption. Biosensors 2019, 9, 1-17. [CrossRef]

35. Paradowska, E.; Arkusz, K.; Pijanowska, D.G. Comparison of Gold Nanoparticles Deposition Methods and Their Influence on Electrochemical and Adsorption Properties of Titanium Dioxide Nanotubes. Materials 2020, 13, 4269. [CrossRef]

36. Arkusz, K. The Influence of Implantation on Mechanical Degradation of the Nanotubular Oxide Layer on Titanium Screws. Adv. Intell. Systems Comp. 2018, 1, 339-347.

37. Arkusz, K.; Nycz, M.; Paradowska, E. Electrochemical Evaluation of the Compact and Nanotubular Oxide Layer Destruction under Ex Vivo Ti6Al4V ELI Transpedicular Screw Implantation. Materials 2020, 13, 176. [CrossRef]

38. Liu, S.; Chen, A. Coadsorption of Horseradish Peroxidase with Thionine on $\mathrm{TiO}_{2}$ Nanotubes for Biosensing. Langmuir 2005, 21, 8409-8413. [CrossRef]

39. Kafi, A.K.M.; Wu, G.; Chen, A. A Novel Hydrogen Peroxide Biosensor Based on the Immobilization of Horseradish Peroxidase onto Au-modified Titanium Dioxide Nanotube Arrays. Biosens. Bioelectron. 2008, 24, 566-571. [CrossRef]

40. Guo, C.; Hu, F.; Li, C.M.; Shen, P.K. Direct electrochemistry of hemoglobin on carbonized titania nanotubes and its application in a sensitive reagentless hydrogen peroxide biosensor. Biosens. Bioelectron. 2008, 24, 819-824. [CrossRef]

41. Chen, D.; Zhang, H.; Li, X.; Li, J. Biofunctionaltitania nanotubes for visible-light-activated photoelectrochemical biosensing. Anal. Chem. 2010, 82, 2253-2261. [CrossRef]

42. Kafi, A.K.M.; Wu, G.; Benvenuto, P.; Chen, A. Highly sensitive amperometric $\mathrm{H}_{2} \mathrm{O}_{2}$ biosensor based on hemoglobin modified $\mathrm{TiO}_{2}$ nanotubes. J. Electroanal. Chem. 2011, 662, 64-69. [CrossRef]

43. Xie, Y.; Zhao, Y. Electrochemical biosensing based on polypyrrole/titania nanotube hybrid. Mat. Sci. Eng. C. 2013, 33, 5028-5035. [CrossRef]

44. Hashemi, A.; Ezati, M.; Mohammadnejad, J.; Houshmand, B.; Faghihi, S. Chitosan Coating of $\mathrm{TiO}_{2}$ Nanotube Arrays for Improved Metformin Release and Osteoblast Differentiation. Int. J. Nanomed. 2020, 15, 4471-4481. [CrossRef]

45. Abdolmajid, E.; Kharazi, H.; Chalaki, M.; Khojasteh, M.; Haghighat, S.; Attar, F.; Nemati, F.; Falahati, M. Titanium oxide nanoparticles fabrication, hemoglobin interaction, white blood cells cytotoxicity, and antibacterial studies. J. Biomol. Struct. Dyn. 2019, 37, 3007-3017. [CrossRef]

46. Xu, J.; Zhang, T.; Zhang, J. Photocatalytic degradation of methylene blue with spent FCC catalyst loaded with ferric oxide and titanium dioxide. Sci. Rep. 2020, 10, 12730-12737. [CrossRef]

47. Kamal Eddin, F.B.; Wing Fen, Y. Recent Advances in Electrochemical and Optical Sensing of Dopamine. Sensors 2020, 20, 1039. [CrossRef]

48. Muramatsu, Y.; Jin, Q.; Fujishima, M.; Tada, H. Visible-light-activation of $\mathrm{TiO}_{2}$ nanotube array by the molecular iron oxide surface modification. Appl. Catal. B Environ. 2012, 19, 74-80. [CrossRef]

49. García-Valverde, M.T.; Lucena, R.; Galán-Cano, F.; Cárdenas, S.; Valcárcel, M. Carbon coated titanium dioxide nanotubes: Synthesis, characterization and potential application as sorbents in dispersive micro solid phase extraction. J. Chromatogr. A 2014, 23, 26-32. [CrossRef]

50. Mei, W.; Daojun, G.; Hulin, L. High activity of novel Pd/TiO 2 nanotube catalysts for methanol electro-oxidation. J. Solid State Chem. 2005, 6, 1996-2000.

51. Rong, Z.; Chen, F.; Jilin, J.; Yifeng, T. A C-reactive protein immunosensor based on platinum nanowire/titania nanotube composite sensitized electrochemiluminescence. Talanta 2019, 5, 1-8. [CrossRef]

52. Mandal, S.S.; Navratna, V.; Sharma, P.; Gopal, B.; Bhattacharyya, A.J. Titania nanotube-modified screen printed carbon electrodes enhance the sensitivity in the electrochemical detection of proteins. Bioelectrochemisty 2014, 98, 46-53. [CrossRef]

53. Sun, S.; He, H.; Yang, C. Effects of $\mathrm{Ca}^{2+}$ and fulvic acids on atrazine degradation by nano-TiO 2 : Performances and mechanisms. Sci. Rep. 2019, 9, 8880. [CrossRef]

54. Lichtenberg, J.Y.; Ling, Y.; Kim, S. Non-Specific Adsorption Reduction Methods in Biosensing. Sensors 2019, 19, 2488. [CrossRef]

55. Vogler, E.A. Protein adsorption in three dimensions. Biomaterials 2012, 33, 1201-1237. [CrossRef] 
56. Cao, C.; Yan, J.; Zhang, Y. Stability of titania nanotube arrays in aqueous environment and the related factors. Sci. Rep. 2016, 6, 23065. [CrossRef]

57. Gongadze, E.; Kabaso, D.; Bauer, S.; Slivnik, T.; Schmuki, P.; Rienen, U.; Iglič, A. Adhesion of osteoblasts to a nanorough titanium implant surface. Inter. J. Nanomed. 2011, 6, 1801-1816.

58. Kulkarni, M.; Flašker, A.; Lokar, M.; Mrak-Poljšak, K.; Mazare, A.; Artenjak, A.; Čučnik, S.; Kralj, S.; Velikonja, A.; Schmuki, P.; et al. Binding of plasma proteins to titanium dioxide nanotubes with different diameters. Int. J. Nanomed. 2015, 18, 1359-7133.

59. Reverberi, R.; Reverberi, L. Factor affecting the antygen-antibody reaction. Blood Transfus. 2007, 5, $227-240$.

60. Ward, L.D.; Zhang, J.G.; Checkey, G.; Preston, B.; Simpson, R.J. Effect of pH and denaturants on the folding and stability of murine interleukin-6. Protein Sci. 1993, 2, 1291-1300. [CrossRef]

Publisher's Note: MDPI stays neutral with regard to jurisdictional claims in published maps and institutional affiliations.

(C) 2020 by the authors. Licensee MDPI, Basel, Switzerland. This article is an open access article distributed under the terms and conditions of the Creative Commons Attribution (CC BY) license (http://creativecommons.org/licenses/by/4.0/). 